\title{
Information space of the land reclamation industry in the digital economy of the agroindustrial complex of the Russian Federation
}

\author{
Alexandra Ugryumova, Mikhail Zamakhovsky, Olesya Grishaeva, and Lyudmila Pautova* \\ Federal State Budgetary Scientific Institution All-Russian Research Institute Raduga, Kolomna, \\ Russian Federation
}

\begin{abstract}
The article considers the current state and peculiarities of the information space of the land reclamation sector of the agroindustrial complex of the Russian Federation. The normative-legal bases of formation and development of the land reclamation industry digitalization are determined. Based on the study results, the authors have developed the structure and mechanism of transformation of the information space of land reclamation in the Russian Federation. In the process of scientific and practical analysis, the formation functions of the information space system of the land reclamation sector in the Russian Federation are classified, and the basic principles of functioning of the digital economy of the land reclamation sector of the agro-industrial complex in the Russian Federation are outlined. Based on the system analysis of modern information space of land reclamation sector, the most acute problems of the process of land reclamation digitalization in the Russian Federation are identified, and the directions of its improvement are proposed.
\end{abstract}

\section{Introduction}

According to the international ranking published by Bloomberg Innovation Index at the end of 2020, Russia ranked 26th among the most innovative economies in the world. However, over the past 5 years, the national economy has lost about 14 positions in this rating, which indicates the deterioration of the situation in the field of digitalization of the country and the formation of processes that hinder the development of the information space of the Russian Federation [1,2]. Such positioning of the Russian Federation in the global digital space requires a thorough analysis of all the processes taking place in this direction and a close study of the industry specifics of digitalization in the country.

\footnotetext{
* Corresponding author: cosidanie35@yandex.ru
} 


\section{Materials and methods}

Theoretical and logical methods, method of system analysis and situational analysis, processing and generalization of research results were used in the process of research.

\section{Results and discussion}

The information space of the land reclamation industry is inseparably connected with the agriculture of the Russian Federation and, consequently, with its digitalization. Given the rapidly expanding digital opportunities for the development of the Russian Federation and its individual territories, access to information resources is a prerequisite for reducing the costs of agricultural enterprises, as well as a condition for increasing the profitability and profitability of their economic activities. The introduction of digital platform solutions empowers the domestic economy [3-5].

The platform "Digital Agriculture" acts as the basis for the information space of agriculture in the Russian Federation, which allows coordination of information in the sectoral development. This project allows the interaction of individual enterprises and organizations of the industry horizontally (among themselves) and vertically, with other authorities and their platforms and services.

The main legislative and legal support of the information space of the land reclamation industry and AIC RF as a whole are normative acts:

- $\quad$ Decree of the President of the Russian Federation of July 21, 2016, No. 350 "On measures to implement the state scientific and technical policy in the interests of agricultural development";

- $\quad$ Decree of the Government of the Russian Federation of March 7, 2008, No. 157 "On Establishment of the System of State Information Support for Agriculture";

- National Program "Digital Economy of the Russian Federation", Russian Government Decree No. 1632-R of July 28, 2017;

- Departmental project "Digital agriculture" within the framework of the State program of development of agriculture and regulation of markets of agricultural products, raw materials, and food, Decree of the Government of the Russian Federation No. 717 dated July 28, 2017, as amended on March 31, 2020.

The goal of the departmental project "Digital Agriculture" is the digital transformation of agriculture through the introduction of digital technologies and platform solutions to ensure technological breakthroughs in the agricultural sector and achieve a 2 -fold increase in productivity at "digital" agricultural enterprises by 2021. [6, 7].

The main objectives of creating and developing a digital platform for the agro-industrial complex were the following directions of improving the information space: operational management of production activities of industry enterprises and organizations, formation of current and strategic plans for their development, increasing the validity and validity of decisions taken, taking into account the increased awareness of the managed objects of the industry.

Currently, only $10 \%$ of arable land in the Russian Federation is digitally cultivated. Failure to use new technologies results in a loss of up to $40 \%$ of crops. Given the need to overcome the technological gap with developed countries, it is assumed that the market share of digital technology in agriculture will grow every year; by 2026, the industry market and computer technology in the industry should grow by at least five times [8].

In this regard, the declared objectives of Digital Agriculture can include:

1. Implementation of digital technologies to ensure advanced technological development of agriculture of the Russian Federation with a growth target of 2 times by 2024 . 
2.Identification of points of growth in the industry's information space, particularly promising digital technologies, and justification of state support measures for agricultural producers in light of the expansion of digitalization processes.

3. Ensuring the interaction of digital divisions that ensure the functioning of the digital space of the industry.

4. Monitoring the implementation of the Digital Agriculture project.

5. Formation of additional professional education areas to ensure the emergence and development of digital competencies for the industry personnel.

The main characteristics of agricultural information space, in general, and the land reclamation sector, in particular, are the following: absence of clearly defined boundaries; possibility of obtaining a variety of information; connection with the activities of public administration subjects or other stakeholders; dynamics of the information space, due to its high variability; structured nature of space, due to its numerous components; security of the information space, as its security against unauthorized access, possible distortion or destruction of information, etc.

The main objectives of creating and developing a digital platform for the agro-industrial complex were the following directions of improving the information space: operational management of production activities of industry enterprises and organizations, formation of current and strategic plans for their development, increasing the validity and validity of decisions taken, taking into account the increased awareness of the managed objects of the industry.

The mechanism of transformation of information space of land reclamation and agriculture in the Russian Federation as a whole is carried out following the functions of its components and can be represented as Fig.1. 


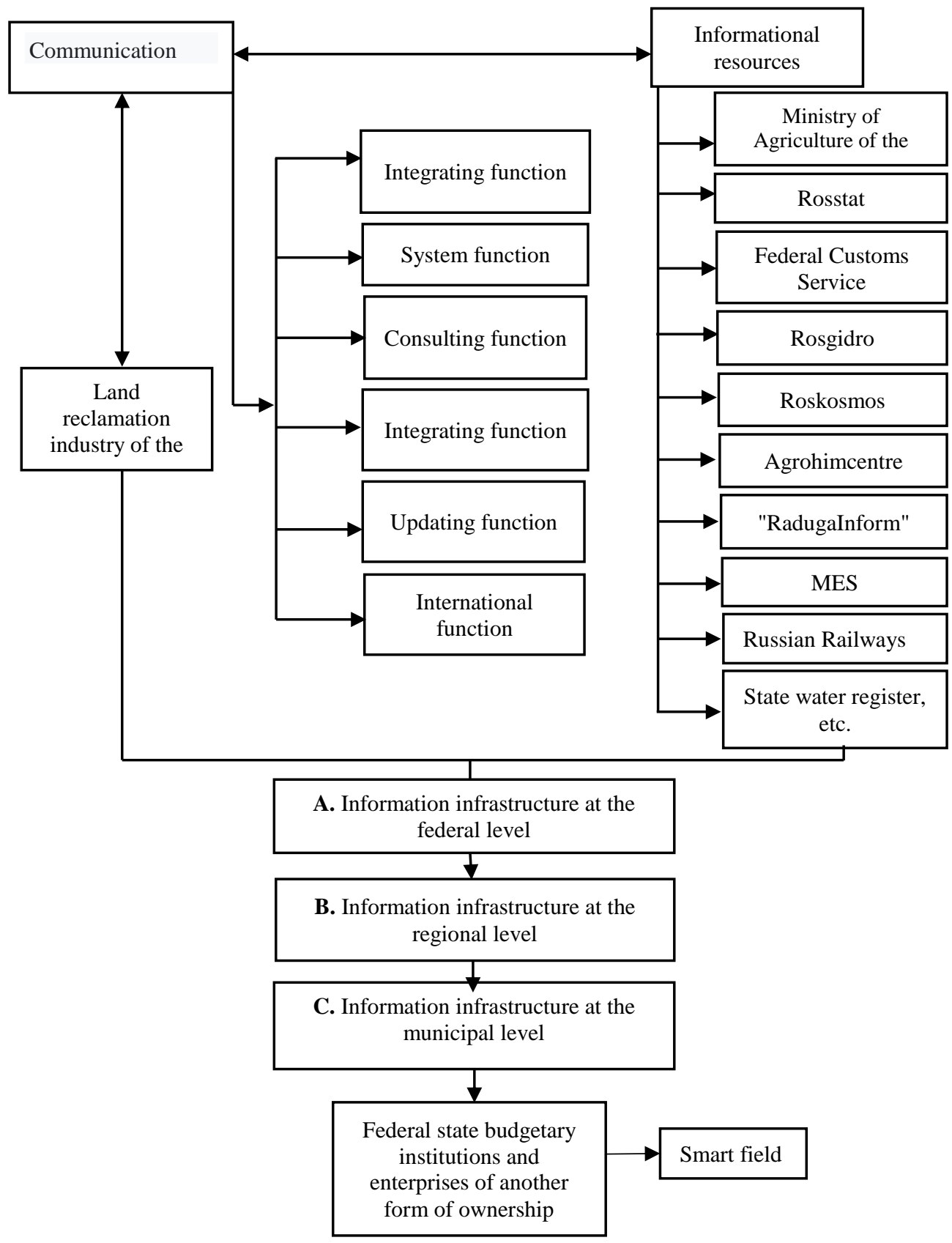

Fig. 1. Mechanism of information space transformation of land reclamation.

Source: compiled by the authors.

The leading functions entrusted with the role of information space system formation should include systemic function, which is entrusted with the collection, systematization, and storage of information; consulting function (providing a variety of services of the information field); communicative function (providing interaction between individual stakeholders); integrating function, which links into a single information space its individual components (in particular, integration with the platforms included in the information resources of the 
industry); actualizing - which is designed to actualize the various interests of various subjects of the information field; an international function, involving the formation of its own resources and infrastructure, contributing to the expansion of information interaction between individual countries.

Each of the sector's information resources elements allows assessing its interaction with the land reclamation sector and revealing the effectiveness of this interaction.

All these factors together allow to implement intelligent planning and forecasting of industry resources, improve the quality of accounting of land reclamation facilities through the introduction of digital certification, increase the level of profitability of individual industry organizations and the industry as a whole, and, consequently, expand the opportunities for import substitution of agricultural products. This dramatically increases the efficiency of providing the necessary information to its consumers, as the information space is updated in real-time.

Thus, digital integration with such structures as RF Ministry of Agriculture, Rosstat, State Water Registry, Federal Customs Service, Roshydromet, EFIS ZSN (unified federal information system on agricultural land), etc. allow not only to obtain reliable information on various issues in real-time but also to form algorithms for decisions aimed at digital land reclamation management $[9,10]$. In particular, in case of emergency, interaction with the information field of Roshydromet and EMERCOM makes it possible to form the value of subsidies and, consequently, adjust the finances allocated in emergencies.

The State Water Registry allows systematizing data on water bodies under different types of ownership of constituent entities of the Russian Federation, municipalities, individuals, legal entities, or individual entrepreneurs. This information resource allows registering water use agreements and decisions on the provision of water bodies for use, as well as information on changes in rights and obligations under water use agreements.

The database portal "Raduga inform", organized by Federal State Budgetary Scientific Institution All-Russian Research Institute Raduga and registered by the state certificate ${ }^{1}$ 2020622674 , allows to form the current and retrospective information about the condition of reclamation systems and their components, separately located hydraulic structures, irrigated and drained lands for each region of Russia [11]. This database provides the formation of passports of FSBI, subordinate to the Department of Land Reclamation of the Ministry of Agriculture of the Russian Federation, passports and technical-operational maps of land reclamation systems, reports on immovable property under the management of institutions; consolidated reports. This information product is recommended for industry specialists, executive authorities of the RF subjects, statistical agencies, scientific and educational institutions. Raduga INFORM portal is entrusted practically all specialized functions on branch information field management, namely: information, communicative, systeminformative and updating that allows considerably improving possibilities of information transfer in land reclamation, improving quality of the branch information field and providing implementation of "real-time operation" principle.

In the work process, several problems hampering the development of precision reclamation in the country were identified. Thus, a low level of digital competencies of most employees responsible for populating the portal databases was recorded. At the same time, insufficient correspondence of portal functionality to modern requirements was noted. It was revealed the necessity of developing a mobile version of the RADUGA INFORM portal, expanding the portal databases, and updating its design, which requires additional investments into the modernization of the branch information field.

Another important information resource is the digitalization of the transport component of the land reclamation industry. In particular, we are talking about such structures as: Roscosmos and Russian Railways. Clear interaction between these resources and reclamation industry structures allows linking agricultural production from reclaimed land in the chain 
"reclaimed field - consumer". Thus, according to Evgeny Charkin, IT Director of Russian Railways, due to software robots, labor productivity at various routine operations has increased from $30 \%$ to $70 \%$ and emphasized that modern digitalization is primarily a contactless interaction within the organization [12]. However, at the same time, the current socio-economic crisis caused by the global pandemic has affected the possibilities of using the digital resources of Russian Railways and reduced the financial flows that were previously planned to be allocated for the development of the information space of the industry. In particular, the mass media published the news about the reduction of the investment program of RZD that was supposed to be spent on the credit funds aimed at improvement of the transport infrastructure management, electronic document circulation, formation of automated workplaces, use of software to form digital twins, etc.

Quality work of Roshydromet and its interrelation with land reclamation is also a prerequisite for clear functioning of the information space of the industry. According to the deputy director for scientific work of the E.K. Fedorov Institute of Applied Geophysics V. Minligareev, nowadays the structure of meteorological observations is characterized by the growth of import dependence and lack of own satellites, leading to a decrease in the forecasting efficiency [13]. This situation not only reduces the efficiency of information resources of the industry and the information space as a whole but can also cause significant economic damage to the national economy of the Russian Federation.

In order to characterize the digital space of land reclamation more objectively, it is advisable to clarify the basic principles of functioning of the industry's digital economy:

1. The modern information space of the industry being a structured and diverse field of economic activity is simultaneously an independent strategic resource. At the same time, there has been a rapid increase in the volume of information used, with a simultaneous intensive expansion of the tools used for information processing and analysis. The information space of the industry falls under the influence of the information crisis due to three main reasons: limited human capacity to process increasing volumes of information; need to filter information to separate necessary from garbage; emergence of arrays of classified information that hinders its processing and analysis.

2. As a consequence of the decline in the efficiency of resources used both in the economy as a whole and in land reclamation, in particular, there is a problem associated with the need to identify in the information field of the land reclamation industry-leading points of growth, providing maximum return on investment in digital technology. Thus, the analytical center of the RF Ministry of Agriculture calculated the impact of information technology on the cost of grain production, which showed that investment in IT products for the agro-industrial complex at the stage of irrigation systems maintenance allows reducing costs by $15.7 \%$ [14].

3. The emergence of two-way, three-way, and more market interactions in the information space, which allow for contact based on an information platform or specialized intermediary. In this case, the key to the success of this interaction is the mandatory presence of all parties to the business process.

\section{Conclusions}

The conducted research of modern information space of land reclamation industry sector allows formulating conclusions:

1. Digitalization of the country's agriculture is hampered by insufficient coverage of the RF territory by the Internet [15]. Such a situation leads to the impossibility of creating and maintaining unified state digital platforms of information resources of the industry and, consequently, the unreality of clear interaction between these resources. In general, the underdevelopment of the information infrastructure of the industry was revealed. 
2. The creation of a modern digital space objectively requires increased public and private investment for this purpose. The existing volume of investment resources not only does not cover the current needs of forming the platform "Digital Agriculture", but also does not correspond to the growing needs of the information space of land reclamation.

3. The level and sophistication of Russian legislation do not meet the needs of the information society and allow for legal hatches that do not prevent the emergence of legal mishaps.

4. There is a pronounced lack of specialists with sufficient competencies to work in the digital economy; there is a lack of IT specialists in the land reclamation industry.

Study was carried out as part of the State Assignment of the Russian Ministry of Agriculture for 2021.

\section{References}

1. Russia in IT ratings. https://www.tadviser.ru/index.php

2. V. Tsirenshchikov, Sovremennaya Evropa 2(3), 104 (2019)

3. National program "Digital Economy of the Russian Federation", order of the Government of the Russian Federation dated July 28, 2017 No. 1632-R

4. E.M. Styrin, Y.D. Rodionova, Public Administration Issues 3, 49 (2020)

5. R. Bukht, R. Heeks, International Organizations Research J. 13(2), 143 (2018)

6. Departmental project "Digital Agriculture": official publication, M.: FGBNU "Rosinformagrotech", 48 (2019)

7. O. A. Gerasimenko, O. V. Nazarova, E. A. Samsonova, Bulletin of the Academy of Knowledge 36(1), 308 (2020)

8. Digitalization of agriculture. http://polit.ru/article/2018/02/21/sk_digital_farming/

9. S.M. Vasiliev, V.N. Shchedrin, A.V. Slabunova, V.V. Slabunov, Melioration and water management 4, 5 (2019)

10. S.A. Manzhina, P.D. Vaneeva, Scientific periodical online journal. BENEFICIUM 2(31), 34 (2019)

11. Information portal of the FGBNU Research Institute "Raduga". https://inform-raduga.ru/

12. Information technology in the Russian Railways. https://www.tadviser.ru/

13. Russian weather forecasts turned out to be import-dependent. https://www.rosbalt.ru/russia/2019/10/18/1808468.html

14. Digital technologies in the agro-industrial complex as objects of intellectual law and sources of the innovative potential of Russia. https://rospatent.gov.ru/content/uploadfiles/presentations/motorin-20092018.pdf

15. A.A. Ugryumova, L.E. Pautova, M.P. Zamakhovsky, National Interests: Priorities and Security 16(4), 631 (2020) 